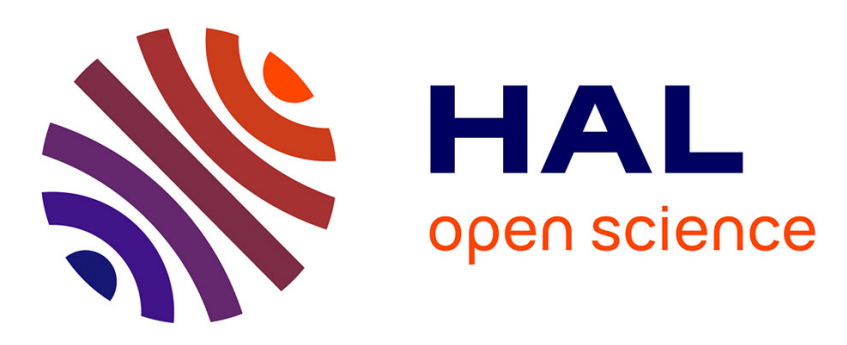

\title{
Evaluation of a surveillance programme for women with a family history of breast cancer
}

\author{
Marta Moreira Reis, Manouche Tavakoli, John A Dewar, David R Goudie, \\ Alan Cook, Lorna Mcleish, Dorothy Young, Jane Kenyon, Christopher \\ Michael Steel
}

\section{To cite this version:}

Marta Moreira Reis, Manouche Tavakoli, John A Dewar, David R Goudie, Alan Cook, et al.. Evaluation of a surveillance programme for women with a family history of breast cancer. Journal of Medical Genetics, 2009, 46 (5), pp.319. 10.1136/jmg.2008.064311 . hal-00552675

\section{HAL Id: hal-00552675 https://hal.science/hal-00552675}

Submitted on 6 Jan 2011

HAL is a multi-disciplinary open access archive for the deposit and dissemination of scientific research documents, whether they are published or not. The documents may come from teaching and research institutions in France or abroad, or from public or private research centers.
L'archive ouverte pluridisciplinaire HAL, est destinée au dépôt et à la diffusion de documents scientifiques de niveau recherche, publiés ou non, émanant des établissements d'enseignement et de recherche français ou étrangers, des laboratoires publics ou privés. 


\section{Evaluation of a surveillance programme for women with a family history of breast cancer.}

Marta M Reis ${ }^{1,2}$, Manouche Tavakoli ${ }^{3}$, John Dewar ${ }^{4}$, David Goudie ${ }^{1}$, Alan Cook $^{1}$, Lorna McLeish ${ }^{1}$, Dorothy Young ${ }^{1}$, Jane Kenyon ${ }^{5}$, Michael Steel ${ }^{1,5^{*}}$

1. Tayside Cancer Family Clinical Service, Ninewells Hospital and Medical School, Dundee. DD1 9SY

2. Department of Surgery and Molecular Oncology, Ninewells Hospital and Medical School, Dundee DD1 9SY

3. Department of Management, University of St Andrews, St Andrews, KY16 9

4. Department of Clinical Oncology, Ninewells Hospital and Medical School, Dundee DD1 9SY

5. Bute Medical School, University of St Andrews, St Andrews KY16 9TS.

* Corresponding author. cms4@st-and.ac.uk Tel 00441334472877

MM Reis, Associate Specialist; Manouche Tavakoli, Senior Lecturer; John Dewar, Consultant Oncologist; David Goudie, Consultant in Clinical Genetics; Alan Cook, Consultant Radiologist; Lorna McLeish, Genetics Nurse specialist; Dorothy Young, Genetics Associate; Jane Kenyon SpR in medicine; Michael Steel, Emeritus Professor in Medical Science.

Running Head: Evaluating surveillance for breast cancer families.

Word count: Abstract 245; Main text 3023 (includes disclaimer). 
Acknowledgements: The work reported in this paper was supported by grants from the Breast Cancer Campaign and the Chief Scientist Office of the Scottish Executive.

The authors are grateful to Mr Derek Colley, Mr Glen Finnie, Mr David Carson and their colleagues in the Ninewells Hospital and Tayside NHS Trust Finance Departments for their patient and helpful response to requests for detailed information on health care costs.

Disclaimers: None of the authors has any financial or other competing interests in the data reported in this paper.

The work reported in this paper has not been published or presented publicly in any form prior to submission. 


\section{Abstract:}

Purpose. To establish health-related costs and benefits of clinical services for women at increased familial risk of breast cancer.

Design. Analysis of costs and outcomes for one UK regional service, supplemented with data from a multi-national collaborative study.

Main outcome measures were aggregate costs for regular clinical examination, mammographic screening and further investigations; breast cancer incidence; proportion of cancers detected at "early" or "late" stage, compared with corresponding data for unscreened women of comparable age; survival in relation to stage at diagnosis; itemised and aggregate costs of management for "early" and "late" stage breast cancer; hence direct health care costs per quality adjusted life year (QALY) gained.

Results. The surveillance programme costs $£ 1500$ per woman (over 15 years). Breast cancer incidence is close to 6 per thousand examinations; $75 \%$ of tumours are detected through screening and $77 \%$ are "early" (path stage 1 or 2). Corresponding figures for unscreened women (including relatives of those attending the breast cancer family clinic) indicate that surveillance achieves a beneficial "stage shift", with reduction in treatment costs and improvement in survival, in about $22 \%$ of cases.

Conclusions. The current clinical service for women at familial risk of breast cancer costs about $£ 4800$ per QALY gained. That figure is sensitive to the rate of detection of breast cancer and the degree of beneficial stage shift achieved. Within the realistic range of estimates for these two parameters, the cost per QALY may be as high as $£ 14000$ or as low as $£ 1000$.

Key words: Breast cancer; familial; surveillance; evaluation. 


\section{Introduction:}

A family history of the disease is recognised as a strong risk factor for breast cancer $^{1}$. Published guidelines recommend that women with multiple affected close relatives, or with one first degree relative affected under age 40 , should be offered annual screening by mammography, with or without clinical examination, from around age 35 to age 50 or $55^{2,3}$. New referrals to centres offering such services are accruing at the rate of around 200 per million population per year ${ }^{4}$. The original guidelines had only a limited evidence base but in the light of experience it is now possible to evaluate the costeffectiveness of surveillance. This report is based principally on findings from a single clinic, centred on Dundee, in Tayside, Scotland.

Factors determining cost effectiveness of a service for women with a family history of breast cancer are the number and cost (both financial and psychological) of investigations carried out, number of breast cancers detected, pathological stages of these cancers, cumulative costs of treatment and outcomes (recurrence rate and overall survival). The most valid comparison would be with corresponding costs and outcomes for prospectively ascertained women with comparable family histories who had not been enrolled in any surveillance programme. However, for ethical and practical reasons it is not possible to randomise such women in a controlled trial. Therefore comparisons are based on published data for Scottish and other populations and on retrospective analysis, first of a series of Tayside 
women diagnosed with breast cancer before age 50 and second, of young relatives of our index cases who had themselves suffered from breast cancer. Neither group had been enrolled in any screening programme before age 50 .

\section{Patients and methods:}

Ethical approval for elements of the study which involved collection of patientspecific data was obtained from the Tayside Medical Research Ethics committee.

Over 11 years from January 1995, 46 breast cancers were diagnosed among 42 women enrolled in the Tayside breast cancer family clinic surveillance program. Seven of these occurred in women carrying a germ-line mutation in BRCA1 or BRCA2. Mean age at diagnosis was 48 years. For comparison we identified a consecutive series of 40 women diagnosed with breast cancer under the age of 50, in the same hospital, since 1995 (allowing a minimum of five years follow-up). Pathological stage at presentation and five year recurrence rates were recorded for both groups (Table 1). In addition, from the families of 32 affected patients (excluding BRCA mutation-bearing families) we identified 37 relatives who had been diagnosed with breast cancer under the age of 55 and who had either never had access to pre-symptomatic screening or had been diagnosed at the first (prevalent) round of the UK National Breast Screening Program (NBSP), which offers mammography at 3 year intervals from age 50. In most instances, the relative's diagnosis had been recorded at first clinic attendance of our patient, confirmed in the course 
of family risk assessment and updated at subsequent annual clinic visits. Data on outcome were documented for the majority.

Our local findings were compared with the much larger dataset (442 recorded cancers) compiled from several collaborating European Cancer Family centres, including our own ${ }^{5-7}$ to confirm that data generated from the limited Tayside series were not unrepresentative.

All procedures carried out in the Breast Cancer Family clinic were tabulated over a 30 month period to obtain accurate figures for surveillance $\operatorname{costs}^{8}$. For each clinic patient in whom breast cancer was diagnosed, subsequent investigations, surgical and radiotherapeutic procedures, hospital in-patient periods, out-patient clinic visits and drugs used were recorded and detailed unit costs were derived by reference to published UK data ${ }^{9}$, updated and supplemented where necessary by information from the Scottish Health Statistics on Breast Cancer (ISD Scotland "blue book"). Additional cost details were provided by senior staff of the Finance Department, Ninewells Hospital and Medical School, Dundee and from the Division of Financial Performance Management for NHS Tayside.

Our analysis involves the following assumptions, all consistent with the observed data presented below, with recent reviews of clinical aspects of breast cancer ${ }^{10,11}$ and with published findings from breast cancer family services elsewhere in the UK and beyond ${ }^{5-7,12-14}$. 
1. Within a "family history" surveillance programme, breast cancers arise at a rate of six per thousand annual examinations and $75 \%$ are detected at screening.

2. Seventy-seven percent of these cancers are "early stage" (Path T1/2) and node-negative at diagnosis.

3. Fifty-five percent of breast cancers arising in women under age 50 who have not participated in any screening programme are "early stage" and node-negative.

4. Path stage T1-2 node-negative breast cancers have a $70 \%$ probability of complete eradication ("cure") by primary surgery, radiotherapy and, where appropriate, adjuvant chemotherapy.

5. "Late" (node positive) breast cancers have only a 30\% probability of "cure" by primary surgery, radiotherapy and adjuvant chemotherapy.

6. Those not "cured" by their primary treatment (30\% of "early" and $70 \%$ of "late" cases) will require additional treatment and investigations, often involving expensive drugs and are likely ultimately to require palliative care.

7. The quality of life for "cured" breast cancer patients is good ${ }^{15-17}$ and, for women diagnosed at around 50 years of age, "cure" of breast cancer provides a further 25 years of life (25 QALYs). 


\section{Results:}

In the 11 year study period, the Tayside "family history" surveillance programme carried out 8000 annual screens, comprising clinical examination of the breasts and two-view mammography. The yield of 46 breast cancers therefore represents a rate of 5.8 per thousand examinations. As shown in table 1a, $34(74 \%)$ were detected at screening and 36 (78.5\%) were "early" stage (Path T1-T2, $\mathrm{N}^{0}$ ). Five year disease-free survival has been $100 \%$ for the 29 cases with this length of follow-up. By contrast, for the 40 women (unselected for family history) diagnosed under age 50, who had never been enrolled in a screening programme, only $55 \%$ presented at a similarly early stage and five year disease-free survival was $82.5 \%$. For the 37 affected relatives of our index cases who had never had access to regular screening, 11 had died from breast cancer within 5 years of diagnosis, 6 more within ten years and only 11 were known to be alive 5 or more years from diagnosis (Table 1b).

Table 2 records resource use, with unit and cumulative costs, calculated for "typical" pre-menopausal women diagnosed with "early" or "late" stage beast cancer. These calculations take account of the different proportions of "early" and "late" breast cancers expected to be "cured" by primary treatment and hence the varying requirement for "second line" drugs, palliative care and other components of management for advanced breast cancer. They demonstrate that the mean cost for an "early" cancer is $£ 17456$, and for a 
"late" cancer $£ 45328$, a difference of $£ 27872$ per patient. Within the "early stage" category, $15 \%$ are assumed to be DCIS since detection at this "precancerous" stage will prevent later development of invasive cancer, which is an important purpose of the screening programme ${ }^{5}$. Inclusion of DCIS cases, however, does not materially affect estimates of benefit from screening in this population since ten year survival for invasive breast cancer in women without BRCA1/2 mutations, diagnosed at stage 1 or 2 , exceeds $85 \%{ }^{7}$.

Using these cost figures as a base, we applied the finding that surveillance increases the proportion of "early stage" breast cancers diagnosed in young women from $55 \%$ to $77 \%$ (Table 1, adjusted slightly downwards by reference to the larger European dataset $\left.^{7}\right)$. Thus, for every hundred breast cancers arising in women enrolled in the programme, 22 are "transferred" from the "poor" to the "good" prognosis category hence, in cost terms, from the left to the right hand column of Table 2, with a total saving in direct health care costs of $£ 613184(22 \times £ 27872)$.

The Tayside "breast cancer family history" service currently undertakes 1000 screens per year so, from the above figures, the shift to earlier stage at diagnosis of breast cancer would apply to 1.32 women per year (22\% of 6 cancers). The saving would then be £36791 (1.32 x £27872), against a cost of around £100,000 (@£100 per screen). Hence the net annual cost of the Tayside programme is $£ 63209$ ( $£ 100,000$ minus the saving of $£ 36791)$. Now if each woman shifted from "late" to "early" stage diagnosis improves her prospects of "cure" by $40 \%$ (from $30 \%$ to $70 \%$ ) and "cure" adds 25 years of 
good quality life (QALYs), the gain is 13.2 QALYs per year $(25 \times 0.4 \times 1.32)$ at a cost of $£ 4789$ per QALY $(£ 63209 \div 13.2)$.

This ignores the fact that many of these women are in productive employment and/or undertaking important family responsibilities which have an economic value. The true cost is therefore likely to be much lower than $£ 4789$.

Our calculations are particularly sensitive to variations in two parameters, namely the rate of detection of breast cancers in a surveillance programme and the degree of "shift" to earlier stage at diagnosis. As discussed later, we believe the values we have used are realistic but if more optimistic or pessimistic figures are substituted, as shown in table 3, the cost per QALY can range from $£ 13880$ to less than $£ 1000$. Even the higher figure is well below the $\{30,000$ attributed to the UK National Institute for Clinical Excellence, justifying the adoption of new drugs or procedures ${ }^{18}$.

\section{Discussion:}

The costs associated with treatment of breast cancer are not fixed either in time or place. As new drugs emerge, they tend to be increasingly expensive and the indications for their use become ever more circumscribed so that today's conclusions may be rapidly superseded. Practices and prices vary from country to country so the figures we have calculated for the UK may not apply precisely elsewhere. Nevertheless, the costs presented in Table 2 are in line with those quoted recently for a US health care organisation ${ }^{19}$ and with an 
earlier US-based study ${ }^{20}$, both of which confirm in particular the extremely high cost of palliative care in the terminal phase of the illness.

We have assumed an incidence of 6 breast cancers per year per thousand women in a "family history" surveillance programme, marginally higher than the figure we actually observed but substantially lower than reported elsewhere ${ }^{12,21,22}$. In the early years of this study, criteria for enrolment in the programme were less strictly applied than currently. We and others have found that investment in checking, extending and validating reported family histories substantially alters the distribution of assessed risk and allows better targeting of screening ${ }^{8,22,23}$. Applying that principle, as we have done since the late 1990's, should increase the cancer incidence rate among those enrolled in surveillance.

The poor prognosis for breast cancer among young women (unscreened and unselected for family history) is well recognised ${ }^{25-27}$ and there is now substantial evidence that pre-menopausal women with a family history of breast cancer, enrolled in an annual screening programme, can expect a much better outcome ${ }^{7,28}$. Our figures of $75 \%$ of breast cancers in such women being screen-detected and $77 \%$ as small node-negative tumours are conservative in comparison with recently published experience from one large clinic $^{14}$. Five-year disease-free survival is a weak surrogate for long-term "cure" and it can be argued that, through "lead-time bias", this measure exaggerates the benefits of screening. Nevertheless, pathological stage, particularly nodal status, is strongly correlated with long-term outcome as well as with extent and cost of primary treatment ${ }^{1}$. The marked difference, which 
we and others ${ }^{12}$ have confirmed, between screened and unscreened cohorts of young women in this respect is therefore a powerful argument in favour of surveillance.

It remains to be demonstrated how much of the "gain" is attributable to the screening programme. Breast cancers in women with a family history of the disease tend to be of lower grade and to have a better predicted prognosis than sporadic tumours ${ }^{29}$. Follow-up of relevant cohorts have generated conflicting findings ${ }^{30,31}$. The largest and most recent report found, in the absence of special surveillance, no survival advantage for women from "low or moderate" risk families compared to age-matched patients from the general population $^{32}$. There are also data supporting the view that screening of women under 50 (irrespective of family history) can achieve a stage-shift in breast cancers at diagnosis ${ }^{33}$. Our analysis of the outcomes for unscreened affected young relatives of our cohort (with comparable familial risk) shows that screening has a large beneficial effect. Of course the comparison is far from ideal; some data on the relatives are missing; 23 of them were diagnosed and treated more than 20 years ago, when management and outcomes were generally less satisfactory than to-day; there might be a greater incentive for women whose relatives had died from breast cancer to seek advice about familial risk compared to those whose relatives had survived; lead time bias could generate an apparent survival gain of up to two years without actually changing the outcome. Nevertheless, taking all of these caveats into account, there is a striking disparity $(P<0.025)$ between the 10 year survival of $>85 \%$ recorded in the European multi-centre cohort for 
mutation-negative women enrolled in annual "family history" surveillance programmes $^{7}$ and the corresponding figure for our subgroup of unscreened relatives (54\%, at best, if all 9 patients with incomplete follow-up information are assumed to remain disease-free).

Carriers of germ-line BRCA1 mutations appear to represent a distinct subgroup that does not benefit from regular screening as currently practised $^{7,28}$. Although introduction of MRI scanning may change this picture, evidence of survival benefit is awaited. Despite detection of their cancers at an apparently early stage (small, node-negative primaries) recurrence rate is very high. Chemotherapy regimes designed specifically for BRCA1-associated breast cancer (using, for example, platinum-containing agents or PARP inhibitors) show promise and may alter prognosis substantially but trials are still in their early stages. Their results must be taken into account in due course but, for the present, these cases should all be counted in the left hand column of Table 2. Note that this does not apply to BRCA2 mutation-carriers who have a good outcome if screened regularly ${ }^{7}$. Only some $10 \%$ of the Tayside "breast cancer family" clinic patients carry BRCA mutations, with BRCA1 slightly outnumbering BRCA2 carriers. Five of the 46 observed breast cancers in the screened cohort were known (or later found) to be positive for BRCA1 mutations (and two for BRCA2). Placing all of these 5 in the "late stage" category or removing them from the calculations has only minor effects on the figures presented in tables 2 and 3. However prophylactic surgery (bilateral salpingo-oophorectomy plus bilateral total mastectomy) are not only better options at present for women with known BRCA1 mutations but are 
also cost effective, given that the total cost of this surgery is around $£ 11,000$ while the "average" cost of management after a breast cancer has been diagnosed is $£ 44728$ (from Table 2). Recent data from Norway confirm the very low cost per life year gained when prophylactic surgery is adopted by young carriers of BRCA1 mutations ${ }^{34}$. Women carrying BRCA2 mutations are also advised to consider prophylactic salpingo-oophorectomy with a cost of less than $£ 3000$.

Psychological "costs" should not be underestimated. Work in this area suggests that, with support, prophylactic surgery is acceptable to many women at high risk ${ }^{35,36}$ but detailed discussion is beyond the scope of this report.

The psychological price of annual screening, with attendant reminders of breast cancer risk and the anxiety that accompanies the wait for results, applies to all women enrolled in a "family history" surveillance programme. It is difficult to quantify but recent reviews conclude that the impact on general anxiety or cancer-specific worry is broadly neutral ${ }^{37,38}$ and it is clear that women aware of their possible familial risk of breast cancer strongly favour access to regular mammography, regarding it as a comfort rather than a source of anxiety ${ }^{39,40}$.

Previous attempts to calculate the costs and benefits of management options for women at increased genetic risk of breast cancer have been hampered by paucity of objective data. The pioneering 1999 report $^{41}$ of Heimdal and 
colleagues from Norway used standard health insurance charges to measure costs of screening and assumed a $75 \%$ "cure" rate for women who developed breast cancers while in a surveillance programme - not very different from what has subsequently been observed. However they estimated that early diagnosis resulted in 30 added years of life (rather than 25) and, for simplicity, attributed all of this gain to screening. This resulted in a lower cost per life year gained than we have calculated but there is no fundamental conflict between our datasets.

Two Canadian studies undertaken some ten years ago, and an even earlier UK survey, confirm that costs of management of advanced breast cancer are much higher than for early stage disease but all their figures are considerably lower than reported here, reflecting mainly the subsequent introduction of expensive new agents ${ }^{42-44}$.

Griffith and colleagues ${ }^{45}$ undertook a detailed analysis of costs for NHS (UK) cancer genetics services and arrived at figures for QALYs gained through surveillance or prophylactic surgery that, at first sight, appear rather low. However when our own calculations are re-expressed in equivalent terms, the two datasets are consistent. Our estimate of 13.2 QALYs gained per year (1000 screens) reduces to 0.013 QALYs per screen and if each woman in the surveillance program is screened annually for fifteen years, she can expect to gain only 0.19 QALYs. However all of the gain is concentrated in the minority of women (around 9\%) in the program who actually develop breast cancer 
during the period of surveillance. Griffith and colleagues did not attempt to estimate the cost savings achieved through surveillance programmes.

Other published analyse ${ }^{19,46,47}$ have concentrated on carriers of BRCA1 and BRCA2 mutations and, while the advantages of prophylactic surgery (particularly salpingo-oophorectomy) have been emphasised, the important finding that regular surveillance has different efficacy for BRCA1 compared to BRCA2 mutation-carriers has not been recognised.

In conclusion, while financial considerations are not of prime concern in this area of health care $^{48}$, they must be recognised when decisions are made about commissioning new services or evaluating existing ones ${ }^{48}$. We believe our detailed, evidence-based evaluation a surveillance programme for women with a family history of breast cancer makes the case for continuing to support this approach. 
Table 1.

Characteristics of breast cancers in three cohorts of young women.

a)

\begin{tabular}{|l|c|c|}
\hline & "Surveillance" Group & $\begin{array}{c}\text { Unscreened } \\
\text { (population)Group }\end{array}$ \\
\hline Number in group & 46 (42 patients) & 40 (40 patients) \\
\hline $\begin{array}{l}\text { No. (\%) screen- } \\
\text { detected }\end{array}$ & $34(74)$ & 0 \\
\hline $\begin{array}{l}\text { No. (\%) "Early } \\
\text { stage" (T1/2 N) }\end{array}$ & $36(78.5)$ & $22(55)$ \\
\hline $\begin{array}{l}\% \text { Disease-free } \\
\text { at 5 yrs }\end{array}$ & 100 & $\begin{array}{l}\text { Node Negative } 92 \\
\text { Node positive } 72\end{array}$ \\
\hline
\end{tabular}

b)

\begin{tabular}{|c|c|}
\hline & $\begin{array}{l}\text { Relatives of } \\
\text { "surveillance" group }\end{array}$ \\
\hline Number in group & 37 \\
\hline $\begin{array}{l}\text { Mean age } \\
\text { (Range) }\end{array}$ & $\begin{array}{l}45 \text { yrs } \\
(28-54)\end{array}$ \\
\hline $\begin{array}{l}\text { Number }(\%) \text { alive } 5 y r s \\
\text { from diagnosis }\end{array}$ & $25 \quad(68)$ \\
\hline $\begin{array}{l}\text { Number }(\%) \text { alive } 10 \text { yrs } \\
\text { from diagnosis }\end{array}$ & $11^{\star}(29.7)$ \\
\hline $\begin{array}{c}\text { Number (\%) } \\
\text { with incomplete } \\
\text { information }\end{array}$ & $9^{\star *}(24.3)$ \\
\hline \multicolumn{2}{|c|}{$\begin{array}{l}\text { * At least } 3 \text { died later from breast cancer. } \\
\star * \quad 3 \text { with }<10 \text { yrs follow-up, } 6 \text { no information. }\end{array}$} \\
\hline
\end{tabular}


Table 2.

Unit costs for management of breast cancer in NHS and distribution of costs according to stage at diagnosis.

\begin{tabular}{|c|c|c|c|c|}
\hline \multirow[b]{2}{*}{$\begin{array}{l}\text { Component of management and } \\
\text { Unit cost }\end{array}$} & \multicolumn{2}{|c|}{$\begin{array}{l}\text { Late stage } \\
\text { (T3/4 N+) }\end{array}$} & \multicolumn{2}{|c|}{$\begin{array}{l}\text { Early stage } \\
\text { (T1/2 N-) }\end{array}$} \\
\hline & $\%$ * & Cost $^{\star \star}$ & $\%^{*}$ & Cost $^{\star \star}$ \\
\hline Initial inpt. stay (5 nights @£449/nt) & 85 & $£ 1908$ & 100 & $£ 2245$ \\
\hline WLE + Ax Surgery, $£ 1673$ & 15 & $£ 251$ & 60 & $£ 1004$ \\
\hline Mx + Ax surgery, $£ 2421$ & 70 & $£ 1695$ & 0 & $£ 0$ \\
\hline$M x+A x$ surgery + reconstr, $£ 4513$ & 0 & $£ 0$ & 40 & $£ 1805$ \\
\hline Anthracyclines X 6, £1836 & 50 & $£ 918$ & 60 & $£ 1102$ \\
\hline FEC x 6, $£ 3155$ & 50 & $£ 1577$ & 0 & $£ 0$ \\
\hline Taxanes, $£ 9160$ & 70 & $£ 6412$ & 15 & $£ 1374$ \\
\hline Herceptin (2 yrs), £44,000 & 25 & $£ 11,000$ & 5 & $£ 2200$ \\
\hline Bisphosphonates (2 yrs), $£ 4000$ & 50 & $£ 2000$ & 10 & $£ 400$ \\
\hline Tamoxifen (5 yrs), $£ 43$ & 50 & $£ 21$ & 50 & $£ 21$ \\
\hline Radiotherapy (Standard), $£ 1500$ & 100 & $£ 1500$ & 60 & $£ 900$ \\
\hline Palliative radiotherapy, $(£ 400)$ & 70 & $£ 280$ & 15 & $£ 60$ \\
\hline $\begin{array}{c}\text { Palliative care in last year of life } \\
\text { (includes } 15 \text { nights in-patient stay @ } \\
£ 846 \text { ), } £ 25,380\end{array}$ & 70 & $£ 17766$ & 25 & $£ 6435$ \\
\hline TOTAL COST & & 328 & & 456 \\
\hline
\end{tabular}

* Percentage of patients in this category requiring this component

${ }^{* *}$ Cost for "typical" patient in this category - i.e. unit cost $x \%$ requiring it.

WLE = wide local excision; Ax. surgery = axillary surgery; $M X=$ total mastectomy reconstr $=$ breast reconstruction; FEC $=$ chemotherapy regime using 5-fluorouracil, epirubicin and cyclophosphamide) 
Table 3

Effects of changing sensitive parameters (numbers of breast cancers detected per year and percentage of patients who benefit from "stage shift" of their cancer) on cost-effectiveness of surveillance programmes.

\begin{tabular}{|c|c|c|c|c|c|c|}
\hline $\begin{array}{c}\text { No.Breast } \\
\text { Cancers } \\
\text { diagnosed/yr }\end{array}$ & $\begin{array}{l}\% \text { shift to } \\
\text { "curable" } \\
\text { stage }\end{array}$ & $\begin{array}{c}\text { No. Ca Br } \\
\text { Patients } \\
\text { benefitting/yr }\end{array}$ & $\begin{array}{l}\text { QALYs } \\
\text { gained* }^{*}\end{array}$ & $\begin{array}{c}\text { Annual } \\
\text { saving } \\
£^{\star \star}\end{array}$ & $\begin{array}{c}\text { Annual } \\
\text { net } \\
\text { cost } \\
£^{\star \star \star}\end{array}$ & $\begin{array}{c}\text { Cost } \\
\text { per } \\
\text { QALY } \\
£\end{array}$ \\
\hline 6 & 22 & 1.32 & 13.2 & 36791 & 63209 & 4789 \\
\hline 4 & 22 & 0.88 & 8.8 & 24527 & 75473 & 8576 \\
\hline 9 & 22 & 1.98 & 19.8 & 55187 & 44813 & 2263 \\
\hline 6 & 15 & 0.9 & 9 & 25084 & 74916 & 8324 \\
\hline 6 & 30 & 1.8 & 18 & 50170 & 49830 & 2768 \\
\hline 4 & 15 & 0.6 & 6 & 16723 & 83277 & 13880 \\
\hline 4 & 30 & 1.2 & 12 & 33446 & 66554 & 5546 \\
\hline 9 & 15 & 1.35 & 13.5 & 37627 & 62373 & 4620 \\
\hline 9 & 30 & 2.7 & 27 & 75254 & 24746 & 916 \\
\hline
\end{tabular}

*Assumes 10 QALYs per additional patient detected at a "curable"stage.

** Assumes saving of $£ 27872$ per additional patient detected at "curable" stage (from Table 2).

*** Assumes fixed annual screening cost of $£ 100,000$ (1000 women screened) 


\section{References:}

1. Dixon JM (Editor) (2006). ABC of Breast Diseases, $3^{\text {rd }}$ Edition. BMJ Books, London.

2. Evans DGR, Fentiman IS, McPherson K, Asbury D, Ponder BAJ and Howell A(1994). Familial breast cancer. BMJ 308: 183-187.

3. Anderson E, Berg J, Campbell J, Carnaghan H, et al, (2008). Prospective surveillance of women with a family history of breast cancer: auditing the risk threshold. Br J Cancer. 98:840-844.

4. Wonderling D, Hopwood P, Cull A, Douglas F, Watson M, Burn J and McPherson K (2001). A descriptive study of UK cancer genetics services: an emerging response to the new genetics. Br J Cancer 85; 166-170.

5. Moller P, Rei M, Evans G, Vasen H, et al., (1999).Efficacy of early diagnosis and treatment in women with a family history of breast cancer. Dis Markers 15; 179-186.

6. Moller P, Borg A, Evans DG, Haites N, et al., (2002). Survival in prospectively ascertained familial breast cancer: analysis of a series stratified by tumour characteristics, BRCA mutations and oophorectomy. Int J Cancer $101 ; 555-559$. 
7. Moller P, Evans DG, Reis MM, Gregory H, et al., (2007). Surveillance for familial breast cancer: differences in outcome according to $B R C A$ mutation status. Int J Cancer 121; 1017-1020.

8. Reis MM, Young D, McLeish L, Goudie D, et al., (2006). Analysis of referrals to a multi-disciplinary breast cancer genetics clinic: practical and economic considerations. Fam Cancer5; 297-303.

9. Dewar J A (2001). Health economic evaluation of the total costs of care of women with breast cancer. In Mansel R, Smith I, Kunkler I and Miles A, Editors, The effective management of breast cancer, 147-155. Aesculapius Medical Press, London.

10. Rodger A , Stebbing J and Thompson AM (2006), Breast cancer (nonmetastatic). Clin Evid., 15; 1-37

11. Smith IE and Chua S. (2006). Role of systemic treatment in primary operable breast cancer. In Dixon JM, Editor, $A B C$ of Breast Diseases, $3^{\text {rd }}$ Edition, 54-64. BMJ Books, London.

12. Tilanus-Linthorst MM, Bartels CC, Obdeijn Al and Oudkerk M (2000). Earlier detection of breast cancer by surveillance of women at familial risk. Eur J Cancer 36: 514-519. 
13. Brekelmans CT, Seynaeve C, Bartels CC, Tilanus-Linthorst MM, et al, (2001). Effectiveness of breast cancer surveillance in BRCA1/2 mutation carries and women with high familial risk. J Clin Oncol 19: 924-930.

14. Gui GP, Kadayaprath D, Darhouse N, Self J, et al., (2006). Clinical outcome and service implications of screening women at increased breast cancer risk from family history. Eur J Surg Oncol 32; 719-724.

15. Casso D, Buist DSM and Taplin S (2004). Quality of life of 5-10 year breast cancer survivors diagnosed between age 40 and 49 . Health Qual Life Outcomes 2: 25 .

16. Mols F, Vingerhoets AJ, Coebergh JW and van de Poll-Franse LV (2005). Quality of life among long-term breast cancer survivors: a systematic review. Eur J Cancer 41: 2613-32619.

17. Helgesson O, Lissner L, Mansson J and Bengtsson C (2007). Quality of life in cancer survivors as observed in a population study of Swedish women. Scand J Primary Health Care 25: 220-225.

18. Appleby J, Devlin N and Parkin D (2007). NICE's cost effectiveness threshold: how high should it be? BMJ 335; 358-359. 
19. Anderson K, Jacobson JS, Heitjan DF, Zivin JG, et al., (2006). Costeffectiveness of preventive strategies for women with a BRCA1 or BRCA2 mutation. Ann Intern Med 144; 397-406.

20. Berkowitz N, Gupta S, Silberman G (2000). Estimates of the lifetime direct costs of treatment for metastatic breast cancer. Value Health 3: 22-30.

21. Kerilkowske K, Grady D, Rubin SM, Sandrock C and Ernster VL, (1995). Efficacy of screening mammography. A meta-analysis. J Amer Med Assoc $273 ; 149-154$.

22. Kollias J, Sibberling DM, Blamey RW, Holland PAM, et al., (1998). Screening women aged less than 50 years with a family history of breast cancer. Eur J Cancer 34; 878-883.

23. Campbell H, Holloway S, Cetnarskyj R, Anderson E, et al., (2003). Referrals of patients with a family history of breast cancer from primary care to cancer genetics services in S.E.Scotland. Br J Cancer 89; 1650-1656.

24. Brennan P, Shaw T and Claber O (2007). The Teesside cancer family history service: change management and innovation at cancer network level. Fam Cancer 6; 181-187. 
25. Chung M, Chang HR, Bland KI and Wanebo HJ (1996). Younger women with breast carcinoma have a poorer prognosis than older women. Cancer 77; 97-103.

26. Peer PGM, Verbeek ALM, Mravunac M, Hendriks JHCL and Holland R (1996). Prognosis of younger and older patients with early breast cancer. $\mathrm{Br} \mathrm{J}$ Cancer 73; 382-385

27. Yildrim E, Dalgic T and Berberoglu U (2000). Prognostic significance of young age in breast cancer. J Surg Oncol 7; 267-272.

28. Robson ME, Chappius PO, Satagopan J, Wong N, et al., (2004). A combined analysis of outcome following breast cancer: differences in survival based on BRCA1/BRCA2 mutation status and administration of adjuvant treatment. Breast Cancer Res 6; R8-R17

29. Lakhani SR, Gusterson BA, Jacquemeier J, Sloane JP, et al., (2000). The pathology of breast cancer: histological features of cancers in families not attributable to mutations in BRCA1 or BRCA2. Clin Cancer Res. 6; 782-789.

30. Slattery ML, Berry TD and Kerber RA (1993). Is survival among women diagnosed with breast cancer influenced by family history of breast cancer? Epidemiology 4: 543-548. 
31. Malone KE, Daling JR, Weiss NS, et al. (1996). Family history and survival of young women with invasive breast carcinoma. Cancer 78: 1417-1425.

32. Verkooijen HM, Chappius PO, Rapiti E, Vlastos G, Fioretta G, Sarp S, Sappino AP, Schubert H, Bouchardy C (2006). Impact of familial risk factors on management and survival of early-onset breast cancer: a population-based study. Br J Cancer 94: 231-238.

33. Smith RA. (2000). Breast screening among women younger than age 50 : a current assessment of the issues. CA CAncer J Clin. 50; 312-336.

34. Norum J, Hagen Al, Maehle L, Apold J, Burn J and Moller P (2008) Prophylactic bilateral salpingo-oophorectomy (PBSO) with or without a prophylactic bilateral mastectomy (PBM) or no intervention in BRCA1 mutation-carriers: a cost-effectiveness analysis. Eur J Cancer 44: 963-971

35. Eisinger F, Julian-Reynier C, Sobol H, Stoppa-Lyonnet D, et al., (2000). Acceptability of prophylactic mastectomy in cancer prone women. J Amer Med Assoc 283; 202-203.

36. Bebbington Hatcher M and Fallowfield LJ (2003). A qualitative study looking at the psychological implications of bilateral prophylactic mastectomy. Breast 12; 1-9. 
37. Braithwaite D, Emery J, Walter F, Prevost AT and Sutton S (2004).

Psychological impact of genetic counselling for familial cancer: a systematic review and meta-analysis. J Natl Cancer Inst. 96: 122-133.

38. Hopwood, P., Steel, C.M., Burn, J. and McPherson, K. (2004) A randomised comparison of UK genetic risk counselling services for familial cancer: psychosocial outcomes. Br J Cancer 91: 884-892.

39. Julian-Reynier C, Eisinger E, Chabal F, Aurran Y, et al., (1996). Cancer genetics clinics; target populations and consultees' expectations. Eur J Cancer 32A; 398-403.

40. McLeish L. (2003). Demands and needs of women attending two Scottish Family History breast cancer clinics. MSc Thesis, University of Manchester.

41. Heimdal K, Maehle L and Moller P (1999). Costs and benefits of diagnosing familial breast cancer. Dis Markers 15; 167-173

42. Will BP, Berthelot JM, Le Petit C, Tomiak EM, et al.,(2000). Estimates of the cost of breast cancer treatment in Canada. Eur J Cancer 36; 724-735.

43. Wei ES, Trevisan CH, Taylor SCM, Mates D et al., (2001) Health system costs of metastatic breast cancer. Breast Cancer Res Treat. 65; 233-240. 
44. Richards MA, Braysher S, Gregory WM and Rubens RD (1993).

Advanced breast cancer: use of resources and cost implications. Br J Cancer 67: 856-860.

45. Griffith GL, Tudor-Edwards R, Gray J, Butler R, et al., (2004). A microcosting of NHS cancer genetics services. Br J Cancer 92; 60-71.

46. Schrag D, Kuntz KM, Garber JE and Weeks JC. (2000). Life expectancy gains from cancer prevention strategies for women with breast cancer and BRCA1 or BRCA2 mutations. J Amer Med Assoc. 283; 617-624.

47. Calderon-Margalit R and Paltiel O (2004). Prevention of breast cancer in women who carry BRCA1 or BRCA2 mutations: a critical review of the literature. Int J Cancer 112: 357-364.

48. Moller P (2004). Costs and benefits of diagnosing familial breast cancer. Ann Oncol 15 (Suppl 1) 155-159.

49. Turner RD (1999). Economics of genetics from a health commissioning point of view. Dis Markers 15; 175-176. 
The Corresponding Author has the right to grant on behalf of all authors and does grant on behalf of all authors, an exclusive licence (or non-exclusive for government employees) on a world-wide basis to the BMJ Publishing Group Ltd to permit this article (if accepted) to be published in Journal of Medical Genetics and any other BMJPGL products and sublicences such use and exploit all subsidiary rights, as set out in our licence (http://JMG.bmj.com/misc/ifora/licenceform.shtml) 